\title{
Ischaemic stroke - prevention is better than cure
}

\author{
GJ Hankey \\ Consultant Neurologist and Head of Stroke Unit, Department of Neurology, Royal Perth Hospital, Western Australia, and Clinical Professor, \\ School of Medicine E Pharmacology, University of Western Australia, Australia
}

This review is based on a presentation by Professor Hankey at the RCPE Neurology Symposium on 27 November 2009.

KEYWORDS Evidence, health policy, ischaemic stroke, prevention, randomised trials, treatment

DECLARATION OF INTERESTS Professor Hankey has received honoraria for speaking at scientific symposia sponsored by Sanofi Aventis, Boehringer Ingelheim, Bristol Myers Squibb and Pfizer. He has also consulted on advisory boards.
Correspondence to GJ Hankey,

Department of Neurology,

Royal Perth Hospital,

197 Wellington Street,

Perth, Western Australia, 600 I,

Australia

tel. +6I 892242598

e-mail gjhankey@cyllene.uwa.edu.au
The hypothesis that the prevention of ischaemic stroke is more effective than its cure (acute treatment) can be explored by comparing the effect of each strategy on the burden of stroke in a population of one million people in the UK.

\section{THE BURDEN OF STROKE IN THE UK}

Incidence The incidence of ischaemic stroke is about 2.0 (95\% confidence interval $[\mathrm{Cl}]$ : I.8-2.2) per I,000 population per year.' In a population of one million people, there are about 2,000 incident cases of ischaemic stroke each year, of which $1,400(70 \%)$ are first ever and $600(30 \%)$ are recurrent.

Prevalence The age- and sex-adjusted prevalence of stroke has been estimated at between 14.7 per 1,0002 and $17.5(95 \% \mathrm{Cl}: 17.0$ to 18.0$)$ per $1,000,{ }^{3}$ of which about $80-85 \%$ are ischaemic and 15-20\% haemorrhagic strokes. In a population of one million people, there are therefore likely to be at least 12,000 prevalent survivors of ischaemic stroke.

Outcome Among all new cases of ischaemic stroke, about $30 \%$ will die during the year and $35 \%$ will be permanently disabled and dependent on others for help with activities of daily living (modified Rankin score $>3$ ). 4.5 In a population of one million, about $600(30 \%)$ of the 2,000 ischaemic strokes each year are likely to be fatal and 700 (35\%) survivors permanently disabled. ${ }^{4,5}$

\section{WHAT IS THE EFFECT OF ACUTE TREATMENT?}

There are four effective treatments for acute ischaemic stroke (Table I): ${ }^{6-9}$

Thrombolysis Random assignment to intravenous recombinant tissue plasminogen activator (t-PA) within 4.5 hours of ischaemic stroke is associated with a reduction in death or dependency compared with placebo, from $53.0 \%$ (placebo) to $47.1 \%$ (t-PA); absolute risk reduction (ARR): $5.9 \%$; odds ratio (OR): $0.78,95 \% \mathrm{Cl}: 0.68-0.88$ (Table I). ${ }^{6}$
In $2008,1.4 \%$ of patients admitted to hospital in the UK with stroke received intravenous thrombolysis. ${ }^{10}$ As this was less than 10\% of those deemed eligible (arrival at hospital within three hours of stroke onset [now 4.5 hours] and younger than 80 years), ${ }^{\prime \prime}$ it is possible that at least $10 \%$, if not $15 \%$, of ischaemic stroke patients could be thrombolysed.

If $10 \%(n=200)$ of the 2,000 cases of ischaemic stroke that occur in a population of one million could be treated within 4.5 hours of stroke onset with thrombolysis, the number dead or dependent could be reduced by 12 (200 $\times 5.9 \%$ [ARR]), which is about $1 \%$ of all 1,300 new cases of death and dependency due to ischaemic stroke each year in a population of one million (Table I).

Aspirin Random allocation to early aspirin, 160-300 mg once daily, started within 48 hours of onset of ischaemic stroke, is associated with a decrease in death or dependency at the end of follow-up from $46.2 \%$ (control) to $45.0 \%$ (aspirin), ARR: I.2\%, OR: $0.95,95 \% \mathrm{Cl}: 0.9 \mathrm{I}-$ 0.99 (Table I). $^{7}$

In $2008,85 \%$ of inpatients in the UK with acute ischaemic stroke were treated with early aspirin. ${ }^{10}$ If this could be improved upon, and $95 \%(n=I, 900)$ of the 2,000 patients with acute ischaemic stroke could be treated immediately with aspirin, the number of dead or dependent could be reduced by $23(1,900 \times 1.2 \%$ [ARR]), which is $2 \%$ of all I,300 new cases of death and dependency (Table I).

Organised multidisciplinary care in a stroke unit Among 31 trials that compared stroke unit care with an alternative service in a total of 6,936 participants, more organised care in a stroke unit was associated with a significant reduction in death or dependency at final (median one year) follow-up, from $58.7 \%$ (general ward) to $54.4 \%$ (stroke unit); ARR: $4.3 \%$, OR $0.82 ; 95 \% \mathrm{Cl}$ 0.73-0.92 (Table I). ${ }^{8}$ The national sentinel audit of treatment of hospitalised stroke patients in the UK indicated that in $2008,68 \%$ of patients admitted with an acute stroke spent more than half of their admission on 
TABLE I Summary of the effectiveness of treating 2,000 ischaemic stroke patients each year in a population of one million people

\begin{tabular}{|c|c|c|c|c|c|c|}
\hline \multirow{2}{*}{$\begin{array}{l}\text { Strategyl } \\
\text { intervention }\end{array}$} & \multirow{2}{*}{$\begin{array}{l}\text { Target } \\
\text { population } \\
\text { (\% of all } \\
\text { ischaemic } \\
\text { stroke } \\
\text { patients) }\end{array}$} & \multicolumn{2}{|c|}{ Death or dependency } & \multirow{2}{*}{$\begin{array}{l}\text { Absolute risk } \\
\text { reduction } \\
\text { (ARR) }\end{array}$} & \multirow{2}{*}{$\begin{array}{l}\text { No. of dead } \\
\text { and dependent } \\
\text { stroke survivors } \\
\text { avoided per } \\
\text { year in a } \\
\text { population of } \\
\text { one million }\end{array}$} & \multirow{2}{*}{$\begin{array}{l}\% \text { of } I, 300 \text { dead } \\
\text { and dependent } \\
\text { stroke survivors } \\
\text { avoided per } \\
\text { year in a } \\
\text { population of } \\
\text { one million }\end{array}$} \\
\hline & & Control & Intervention & & & \\
\hline Nil & $\begin{array}{l}2,000 \text { ( } 0.2 \% \text { of } \\
\text { pop. of I million) }\end{array}$ & $65.0 \%$ & N/A & 0 & 0 & 0 \\
\hline Thrombolysis & $200(10 \%)$ & $53.0 \%$ & $47.1 \%$ & $5.9 \%$ & 12 & 1 \\
\hline Aspirin & $1,900(95 \%)$ & $46.2 \%$ & $45.0 \%$ & $1.2 \%$ & 23 & 2 \\
\hline Stroke unit & $\mathrm{I}, 600(80 \%)$ & $58.7 \%$ & $54.4 \%$ & $4.3 \%$ & 69 & 5 \\
\hline $\begin{array}{l}\text { Decompressive } \\
\text { surgery }\end{array}$ & $40(2 \%)$ & $76.5 \%$ & $60.2 \%$ & $16.3 \%$ & 7 & 0.5 \\
\hline
\end{tabular}

a stroke unit. ${ }^{10}$ If this could be improved upon, and $80 \%$ $(n=1,600)$ of the 2,000 patients with acute ischaemic stroke could be treated by means of organised inpatient stroke unit care, the number of dead or dependent could be reduced by 69 (I,600 x 4.3\% [ARR]), which is $5 \%$ of all 1,300 new cases of death and dependency in a population of one million (Table I).

Decompressive hemicraniectomy Random assignment to decompressive hemicraniectomy within 48 hours of onset of symptoms of malignant middle cerebral artery territory infarction is associated with a reduction in death or dependency from $76.5 \%$ (conservative) to $60.2 \%$ (surgery); ARR 16.3\%, $95 \% \mathrm{Cl}-0.1-33.1 \%$. ${ }^{9}$ If $2 \%$ (40) of the 2,000 patients with acute ischaemic stroke had malignant middle cerebral infarction causing neurological deterioration, which was treated by means of decompressive hemicraniectomy," the number of dead or dependent could be reduced by seven $(40 \mathrm{x}$ $16.3 \%$ [ARR]), which is about $0.5 \%$ of all I,300 new cases of death and dependency (Table I).

Summary The above calculations suggest that optimal acute treatment of all 2,000 incident cases of ischaemic stroke each year could save up to III (9\%) of the I,300 new cases from death or dependency. This modest effect is consistent with that suggested by other authors, ${ }^{12}$ and observed in 35 population-based studies which showed no significant decline in early (2I-day to one-month) case fatality after stroke between 1970 and $2008 . .^{13}$ These data indicate that recent advances in acute treatments for stroke have not translated into significant declines in early case fatality. ${ }^{13}$

\section{THE EFFECT OF STRATEGIES FOR PREVENTION OF RECURRENT ISCHAEMIC STROKE}

The risk of recurrent stroke after an ischaemic stroke or transient ischaemic attack (TIA) is highest in the first few weeks, ${ }^{14}$ after which it declines to a nadir at about three years and then gradually increases. Over the first five years, the average annual risk of stroke is up to about $5 \%$ per year. ${ }^{15}$ In a population of one million, among whom there are likely to be at least 12,000 prevalent survivors of ischaemic stroke (see above), ${ }^{2,3}$ the number of recurrent strokes each year is about 600 (5\%). ${ }^{15}$ The strategies that have been proven to be effective in preventing recurrent ischaemic stroke include early carotid endarterectomy, antiplatelet therapy, anticoagulation and vascular risk factor control. ${ }^{16-28}$

Carotid revascularisation Random assignment of patients with recently symptomatic $70-99 \%$ carotid stenosis to carotid endarterectomy (vs no endarterectomy) is associated with a reduction in risk of any stroke or death from about $6.5 \%$ per year (no surgery) to about $3.5 \%$ per year (with surgery); relative risk reduction (RRR): $48 \%$ (95\% Cl: $36-60 \%$ ), ARR: $3.0 \% .{ }^{16} \mathrm{As}$ patients with recently symptomatic carotid stenosis (i.e. within days to weeks of an incident ischaemic stroke or TIA) comprise only about $15 \%$ of incident ischaemic strokes and TIA, it is likely that carotid endarterectomy would be appropriate for about 300 (I5\% of 2,000) incident ischaemic stroke patients (Table 2).

Treating 300 patients by means of carotid endarterectomy is likely to prevent nine $(300 \times 3 \%$ [ARR]) of the 600 recurrent ischaemic strokes each year (i.e. I.5\%) (Table 2). It is unlikely that endovascular revascularisation of the symptomatic carotid artery, by means of carotid angioplasty/stent, would offer any advantages over carotid endarterectomy. ${ }^{17}$

Aspirin Aspirin reduces the relative risk of recurrent stroke and other major vascular events by about 13\% (95\% Cl: 6-19\%) compared with controls. ${ }^{18}$ Among 12,000 prevalent survivors of ischaemic stroke, of whom about $85 \%$ would have an arterial pathology as the cause for which aspirin would be indicated, about $77 \%$ $(n=9,240)$ would probably be able to tolerate aspirin. 
TABLE 2 Summary of the effectiveness of interventions for the (secondary) prevention of recurrent stroke among 10,000 prevalent and 2,000 incident stroke and transient ischaemic attack survivors in a population of one million people

\begin{tabular}{|c|c|c|c|c|c|c|c|}
\hline \multirow[t]{2}{*}{ Strategy/intervention } & \multirow[b]{2}{*}{\begin{tabular}{|l|} 
Target \\
population \\
(\% of all \\
cases of \\
prevalent \\
and \\
incident \\
ischaemic \\
stroke)
\end{tabular}} & \multicolumn{2}{|c|}{ Stroke risk per year } & \multirow{2}{*}{$\begin{array}{l}\text { Relative risk } \\
\text { reduction } \\
\text { (RRR) } \\
(95 \% \mathrm{Cl})\end{array}$} & \multirow{2}{*}{$\begin{array}{l}\text { Absolute } \\
\text { risk } \\
\text { reduction } \\
\text { (ARR) }\end{array}$} & \multirow[b]{2}{*}{\begin{tabular}{|l|} 
No. of \\
strokes \\
avoided \\
per year \\
among \\
target \\
population
\end{tabular}} & \multirow[b]{2}{*}{\begin{tabular}{|l|}
$\%$ of 600 \\
recurrent \\
ischaemic \\
strokes \\
avoided \\
each \\
year in a \\
population \\
of one \\
million
\end{tabular}} \\
\hline & & Control & Intervention & & & & \\
\hline Nil & 12,000 & $5.0 \%$ & $N / A$ & 0 & 0 & 0 & $0 \%$ \\
\hline Carotid revascularisation & $\begin{array}{l}300(15 \% \text { of } \\
2,000)\end{array}$ & $6.5 \%$ & $3.5 \%$ & $48 \%(38-60 \%)$ & $3.0 \%$ & 9 & $1.5 \%$ \\
\hline Aspirin & $9,240(77 \%)$ & $5.0 \%$ & $4.4 \%$ & $13 \%(6-19 \%)$ & $0.7 \%$ & 60 & $10 \%$ \\
\hline $\begin{array}{l}\text { Aspirin \& ER } \\
\text { dipyridamole }\end{array}$ & $7,800(65 \%)$ & $4.4 \%$ & $3.6 \%$ & $18 \%(8-28 \%)$ & $0.8 \%$ & 51 & $8 \%$ \\
\hline Clopidogrel & \multicolumn{7}{|c|}{ As for aspirin + ER dipyridamole } \\
\hline Anticoagulants & $960(8 \%)$ & $12.0 \%$ & $4.0 \%$ & $61 \%(37-75 \%)$ & $7.3 \%$ & 70 & $12 \%$ \\
\hline $\begin{array}{l}\text { Blood pressure-lowering } \\
\text { (by } 10 \mathrm{~mm} \mathrm{Hg} \text { systolic) }\end{array}$ & $10,800(90 \%)$ & $5.0 \%$ & $3.3 \%$ & $34 \%(21-44 \%)$ & $1.7 \%$ & 184 & $31 \%$ \\
\hline $\begin{array}{l}\text { LDL-cholesterol-lowering } \\
\text { (by I mmol// LDL) }\end{array}$ & $9,600(80 \%)$ & $5.0 \%$ & $4.4 \%$ & $12 \%(1-22 \%)$ & $0.6 \%$ & 58 & $10 \%$ \\
\hline HbA $_{\mathrm{cc}}$-lowering (by $0.9 \%$ ) & $2,400(20 \%)$ & $5.0 \%$ & $4.65 \%$ & $7 \%(-6-19 \%)$ & $0.35 \%$ & 8 & $1 \%$ \\
\hline $\begin{array}{l}\text { Cessation of } \\
\text { cigarette smoking }\end{array}$ & $2,400(20 \%)$ & $5.0 \%$ & $2.6 \%$ & $47 \%$ & $2.4 \%$ & 58 & $10 \%$ \\
\hline
\end{tabular}

Treating 9,240 ischaemic stroke survivors with aspirin for one year would be expected to reduce the stroke rate from $5.0 \%$ (control) to $4.35 \%$ (aspirin); RRR 13\%, ARR $0.65 \%$. This is a saving of 60 recurrent strokes per year $(9,240$ patients $\times 0.65 \%$ [ARR]), which is about $10 \%$ of all 600 recurrent strokes (Table 2 ).

Aspirin and extended-release dipyridamole Compared with aspirin, the combination of aspirin and extended release (ER) dipyridamole reduces the relative risk of stroke and other major vascular events by about $18 \%(95 \%$ Cl: 8-28\%) in patients with previous TIA or ischaemic stroke of arterial origin. ${ }^{19}$ Among the 9,240 prevalent survivors of ischaemic stroke who can tolerate aspirin, perhaps about 7,800 (65\%) could tolerate the combination of aspirin and ER dipyridamole, because dipyridamole causes headache sufficient to prompt discontinuation in about $10 \%$ of patients. ${ }^{20}$ Treating 7,800 ischaemic stroke survivors with aspirin plus ER dipyridamole for one year would be expected to reduce the stroke rate from $4.35 \%$ (aspirin) to $3.6 \%$ (aspirin and ER dipyridamole); RRR $18 \%$, ARR $0.65 \%$. This is a saving of 51 recurrent strokes per year $(7,800$ patients $\times 0.65 \%$ [ARR]), which is about $8 \%$ of all 600 recurrent strokes (Table 2 ).

Clopidogrel The effect of aspirin combined with ER dipyridamole probably also applies to clopidogrel, because a direct comparison of clopidogrel $75 \mathrm{mg}$ daily with the combination of aspirin $25 \mathrm{mg}$ and ER dipyridamole $200 \mathrm{mg}$ bd in 20,332 ischaemic stroke patients showed no significant difference between either regimen in preventing recurrent stroke (9.0\% aspirin + ER-dipyridamole vs $8.8 \%$ clopidogrel; HR: I.0I; 95\% Cl: 0.92-I.I I). ${ }^{21}$

Anticoagulation For patients with TIA or ischaemic stroke due to embolism of thrombus from the heart, particularly atrial fibrillation (AF), oral anticoagulation with adjusted-dose warfarin, maintaining an international normalised ratio (INR) of 2.0-3.0, reduces the relative risk of recurrent stroke or systemic embolism by about $61 \%$ (95\% Cl: $37-75 \%$ ), from about I2\% (control) to $4.7 \%$ (warfarin) per year (ARR 7.3\%). ${ }^{22-24}$ Among 12,000 prevalent survivors of ischaemic stroke, about I,800 ( $15 \%$ ) would have cardiac embolism (e.g. atrial fibrillation) as the cause (for which warfarin would be indicated), and about 960 (8\%) would probably take warfarin. Treating 960 ischaemic stroke survivors with warfarin for one year would be expected to reduce the stroke rate from about $12.0 \%$ (control) to $4.7 \%$ (warfarin); RRR 6I\%, ARR $7.3 \%$. This is a saving of 70 recurrent strokes per year ( 960 patients $\times 7.3 \%$ ARR), which is about $12 \%$ of all 600 recurrent strokes (Table 2$){ }^{22}$

Blood pressure-lowering Reducing blood pressure by $10 \mathrm{~mm} \mathrm{Hg}$ systolic or $5 \mathrm{~mm} \mathrm{Hg}$ diastolic is associated with a reduction in the relative risk of recurrent stroke by $34 \%$ (21-44\%). ${ }^{25}$ Among 12,000 prevalent survivors of ischaemic stroke, blood pressure-lowering would be 
indicated in almost all patients (except a few, such as those with severe bilateral carotid occlusive disease) and tolerated by at least $90 \% \quad(10,800)$. Taking one antihypertensive drug at a standard dose, or three drugs at half standard dose, would reduce the blood pressure by $10 \mathrm{~mm} \mathrm{Hg}$ systolic or $5 \mathrm{~mm} \mathrm{Hg}$ diastolic in patients with a pretreatment systolic blood pressure of $150 \mathrm{~mm} \mathrm{Hg}$, and would be associated with a reduction in the relative risk of recurrent stroke by $34 \%$ (2I to $44 \%$ ), from $5 \%$ (control) to $3.3 \%$ (antihypertensive) per year; ARR: $1.7 \%$. This would avoid about 184 recurrent strokes per year ( 10,800 patients $\times 1.7 \%$ ARR), which is about $31 \%$ of all 600 recurrent strokes (Table 2). Alternatively (or in addition), lifestyle interventions such as physical exercise, alcohol reduction, a low-salt diet and potassium supplementation could realise reductions in blood pressure of $10 \mathrm{~mm} \mathrm{Hg}$ systolic or $5 \mathrm{~mm} \mathrm{Hg}$ diastolic. ${ }^{26}$

Blood cholesterol-lowering Random assignment to a statin is associated with a reduction in low-density lipoprotein (LDL) concentration by about $\mathrm{I} \mathrm{mmol} / \mathrm{l}$ and a reduction in the relative risk of recurrent stroke by $12 \%$ (95\% Cl: I-2l\%), compared with control. ${ }^{27}$ Among 12,000 prevalent survivors of ischaemic stroke, of whom about $85 \%$ would have an arterial pathology as the cause for which a statin would be indicated, about $80 \%(9,600)$ would probably be able to tolerate a statin. Treating 9,600 ischaemic stroke survivors with a statin for one year would be expected to reduce the stroke rate from $5.0 \%$ (control) to $4.4 \%$ (statin); RRR I2\%, ARR $0.6 \%$. This is a saving of 58 recurrent strokes per year $(9,600$ patients $\times 0.6 \%$ ARR), which is about $10 \%$ of all 600 recurrent strokes (Table 2).

Blood glucose-lowering Random assignment to an intensive blood glucose-lowering regimen with a standard regimen that lowers the mean haemoglobin $A_{\mathrm{lc}}\left(\mathrm{HbA}_{\mathrm{lc}}\right)$ concentration by $0.9 \%$ compared with a standard regimen is associated with a non-statistically significant trend toward a reduction in stroke by $7 \%$ (OR: $0.93,95 \% \mathrm{Cl}: 0.8 \mathrm{I}-\mathrm{I} .06) .^{28}$ If lowering mean $\mathrm{HbA}_{\mathrm{lc}}$ by $0.9 \%$ is subsequently proven to be effective in reducing the risk of stroke by $7 \%$, then it is possible that lowering mean $\mathrm{HbA}_{\mathrm{lc}}$ by $0.9 \%$ among the $2,400(20 \%)$ survivors of ischaemic stroke who are diabetic $^{29}$ could reduce the annual risk of stroke by $0.35 \%$ (from $5.0 \%$ to $4.65 \%$ ) and save about eight strokes per year, or $1 \%$ of the 600 recurrent strokes each year.

Cessation of cigarette smoking The relative risk of ischaemic stroke associated with cigarette smoking is I.9 (95\% Cl: I.7-2.2). ${ }^{30}$ Stopping smoking among the $2,400(20 \%)$ survivors of ischaemic stroke who are smokers $^{29}$ could reduce the annual risk of stroke by $47 \%$ (from $5.0 \%$ to $2.6 \%$ ) and save about 58 strokes per year, or 10\% of the 600 recurrent strokes each year. However, these calculations are likely to overestimate the potential risk reduction for smoking as they are not based on evidence from randomised trials, they assume all smokers will successfully stop and they do not consider the effects of a quantitative reduction in smoking (e.g. from 20 to 10 cigarettes per day).

Summary The above calculations suggest that optimal secondary prevention of all 12,000 prevalent and incident cases of ischaemic stroke each year could save a substantial proportion of the 600 recurrent strokes each year (Table 2). Although Table 2 suggests that the total number of recurrent strokes avoided each year could add up to 498 , this is clearly an overestimate as not all strategies are appropriate for all patients (e.g. patients would not be taking an antiplatelet drug as well as an anticoagulant) and not all strategies are likely to be mutually exclusive, working independently of each other.

\section{THE EFFECT OF STRATEGIES FOR THE PREVENTION OF FIRST-EVER STROKE}

Among the 988,000 people in a population of one million who have never experienced an ischaemic stroke, the risk of first-ever ischaemic stroke is about $0.14 \%$ per year.This population of individuals therefore contributes the majority $(70 \% ; n=I, 400)$ of all ischaemic strokes each year. There are two complementary strategies for preventing first-ever stroke in the community:

I. The 'high-risk' approach, which aims to identify individuals at risk of stroke and prescribe treatments to lower the risk.

2. The 'population' (or 'mass') approach, which aims to lower the prevalence and level of causal risk factors for stroke throughout the general population. ${ }^{3 !}$

The former is usually implemented by clinicians and nurses, and will therefore be discussed below, whereas the latter is usually implemented by governments, health organisations and public health physicians.

The 'high-risk' strategies that have been proven to be effective in preventing first-ever ischaemic stroke include lowering of blood pressure and cholesterol, and anticoagulation for individuals with atrial fibrillation. ${ }^{24,25,27,32}$ Other strategies that have not been proven to be effective but may be effective are stopping smoking, lowering $\mathrm{HbA}_{\mathrm{lc}}$ and perhaps aspirin and carotid endarterectomy. ${ }^{28,30,33-35}$

Blood pressure-lowering The prevalence of hypertension (blood pressure $>140 / 90 \mathrm{~mm} \mathrm{Hg}$ ) in Britain is estimated to be $11.7 \%,{ }^{36}$ which is about 115,600 individuals in a population of 988,000 stroke-free people. The adjusted relative risk of ischaemic stroke among people in the community with a history of hypertension is about $3.6(95 \% \mathrm{Cl}: 2.2-5.8) .{ }^{37}$ If the overall risk of first-ever ischaemic stroke in the strokefree population is $0.14 \%$ (see above), then the average annual risk of ischaemic stroke among hypertensives is about $0.51 \%$ per year $(0.14 \% \times 3.6)$. 
If I 15,600 hypertensives have an annual risk of ischaemic stroke of $0.51 \%$, then they are likely to contribute 583 of the I,400 (42\%) first-ever ischaemic strokes each year. This estimate of the population-attributable risk of stroke due to hypertension (42\%) is consistent with other estimates. ${ }^{38}$ Reducing the blood pressure by 10 $\mathrm{mm} \mathrm{Hg}$ systolic or $5 \mathrm{~mm} \mathrm{Hg}$ diastolic is associated with a reduction in the relative risk of first-ever stroke by $46 \%(35-55 \%) .{ }^{25}$

If the 115,600 hypertensives could be identified and treated with lifestyle modifications or medications that produce a sustained reduction in blood pressure by 10 $\mathrm{mm} \mathrm{Hg}$ systolic or $5 \mathrm{~mm} \mathrm{Hg}$ diastolic, then the rate of stroke could be reduced from $0.5 \mathrm{I} \%$ (control) to $0.28 \%$ (antihypertensive); RRR $46 \%$, ARR $0.23 \%$. This would realise a saving of 266 strokes (II5,600 $\times 0.23 \%$ ) each year, which is $19 \%$ of all 1,400 first-ever strokes in a population of one million people (Table 3). ${ }^{25,25}$

Blood cholesterol-lowering The prevalence of hypercholesterolaemia (total blood cholesterol $>6.5 \mathrm{mmol} / \mathrm{l}$ or treated hypercholesterolaemia) among adults in the UK aged $35-64$ is about $40 \% .^{39}$ Among the whole population, the prevalence of hypercholesterolaemia is about $20 \%$, which is about 197,600 individuals in a population of 988,000 stroke-free people..$^{40}$ The relative risk of a first-ever ischaemic stroke associated with an increase in LDL cholesterol by $1 \mathrm{mmol} / \mathrm{l}$ is about 1.36 (95\% Cl: I.28-I.92). ${ }^{27}$ This estimate is derived from the inverse of the reduction in relative risk of first-ever stroke of $36 \%$ (95\% Cl: $22-48 \%$ ) associated with a reduction in LDL cholesterol concentration by $1 \mathrm{mmol} / \mathrm{I}$ among stroke-free individuals assigned statins (vs control) in clinical trials of statin therapy. ${ }^{27,41}$

If the overall risk of first-ever ischaemic stroke in the stroke-free population is $0.14 \%$ (see above), then the average annual risk of ischaemic stroke among hypercholesterolaemics is about $0.19 \%$ per year $(0.14 \% \times 1.36)$. If 197,600 hypercholesterolaemics have an annual risk of ischaemic stroke of $0.19 \%$, they are likely to contribute 375 of the I,400 (27\%) first-ever ischaemic strokes each year. If the 197,600 hypercholesterolaemics could be identified and treated with a statin sufficient to lower LDL cholesterol concentration by $1 \mathrm{mmol} / \mathrm{l}$, then stroke could be reduced by $36 \%$, from $0.19 \%$ (control) to $0.14 \%$ (statin); ARR $0.05 \%$, and realise a saving of 99 strokes each year $(197,600 \times 0.05 \%)$, which is $7 \%$ of all I,400 first-ever strokes in a population of one million (Table 3)..$^{27,41}$

Anticoagulation for atrial fibrillation The prevalence of atrial fibrillation among adults $>40$ years is about $2.3 \% .^{42}$ In a population of 988,000 stroke-free individuals, about $43 \%(425,000)$ are aged $>40$ years, of whom about $2.3 \%(9,775)$ have atrial fibrillation. ${ }^{42}$ The relative risk of ischaemic stroke associated with atrial fibrillation is about 5.0..$^{43,44}$ If the overall risk of first-ever ischaemic stroke in the stroke-free population is $0.14 \%$ (see above), then the average annual risk of ischaemic stroke among individuals with atrial fibrillation is about $0.7 \%$ per year $(0.14 \% \times 5)$. If 9,775 stroke-free individuals with atrial fibrillation have an annual risk of ischaemic stroke of $0.7 \%$, they are likely to contribute $68(5 \%)$ of the I,400 first-ever ischaemic strokes each year.

Random assignment of individuals with nonvalvular atrial fibrillation to adjusted-dose warfarin is associated with a reduction in stroke by $64 \%(95 \% \mathrm{Cl}, 49-74 \%)$ compared with control..$^{24}$ If half of the $9,775(n=4887)$ individuals with atrial fibrillation could be identified and treated with warfarin, then stroke could be reduced from $0.7 \%$ (control) to $0.25 \%$ (anticoagulation); RRR 64\%, ARR $0.45 \%$, realising a saving of 22 strokes each year $(4,887 x$ $0.45 \%$ ), which is $1.6 \%$ of all 1,400 first-ever strokes in a population of one million (Table 3). ${ }^{24}$

Cessation of cigarette smoking The prevalence of cigarette smoking among adults $>16$ years in the UK is about $23 \%{ }^{45}$ In a population of 988,000 stroke-free individuals, about $80 \%(790,400)$ are aged $>16$ years, of whom about $23 \%(181,792)$ are smokers. ${ }^{45}$ The relative risk of ischaemic stroke associated with cigarette smoking is about $1.9\left(95 \% \mathrm{Cl}\right.$ : I.6- 2.2). ${ }^{30}$

If the overall risk of first-ever ischaemic stroke in the stroke-free population is $0.14 \%$ (see above), then the average annual risk of ischaemic stroke among smokers is about $0.27 \%$ per year $(0.14 \% \times 1.9)$. If 181,792 strokefree smokers have an annual risk of ischaemic stroke of $0.27 \%$, they are likely to contribute $485(35 \%)$ of the I,400 first-ever ischaemic strokes each year.

If the relative risk of ischaemic stroke associated with smoking really is 1.9 , then stopping smoking among the 181,792 stroke-free smokers could reduce the annual risk of stroke from $0.27 \%$ to $0.14 \%$ (RRR $47 \%$, ARR $0.13 \%$ ) and save about 236 strokes per year, or $17 \%$ of the 600 recurrent strokes each year.

However, stroke-free smokers may have little motivation to stop smoking (unlike smokers who experience a stroke). A meta-analysis of seven randomised controlled trials (RCTs) of nicotine replacement therapy (gum, inhaler or patch) vs placebo for 6-18 months in 2,767 smokers who had no intention to quit smoking reported that, compared with $3.3 \%$ of smokers assigned placebo who attained sustained abstinence from smoking for six months, $6.7 \%$ of smokers assigned nicotine replacement therapy attained sustained abstinence from smoking for six months (relative risk $2.06,95 \% \mathrm{Cl}$ : 1.3-3.I; absolute increase $3.4 \%)^{46}$

If all 181,792 smokers were to try nicotine replacement therapy, 3.4\% $(5,454)$ were to stop smoking for at least six months (as observed in the RCTs) and stopping 
TABLE 3 Summary of the effectiveness of drug therapies for the (primary) prevention of first-ever stroke in a population of one million people

\begin{tabular}{|c|c|c|c|c|c|c|c|c|}
\hline \multirow{2}{*}{$\begin{array}{l}\text { Strategyl } \\
\text { intervention }\end{array}$} & \multirow{2}{*}{$\begin{array}{l}\text { Target } \\
\text { population } \\
\text { (\% of } \\
\text { general } \\
\text { population) }\end{array}$} & \multirow{2}{*}{$\begin{array}{l}\text { Relative } \\
\text { risk } \\
(95 \% \mathrm{Cl})\end{array}$} & \multicolumn{2}{|c|}{ Stroke risk per year } & \multirow{2}{*}{$\begin{array}{l}\text { Relative } \\
\text { risk } \\
\text { reduction } \\
(\mathbf{R R R}) \\
(95 \% \mathrm{Cl})\end{array}$} & \multirow{2}{*}{$\begin{array}{l}\text { Absolute } \\
\text { risk } \\
\text { reduction } \\
(\mathrm{ARR})\end{array}$} & \multirow[b]{2}{*}{$\begin{array}{l}\text { No. of } \\
\text { strokes } \\
\text { avoided } \\
\text { per year } \\
\text { among } \\
\text { target } \\
\text { population }\end{array}$} & \multirow[b]{2}{*}{$\begin{array}{l}\text { \% of I,400 } \\
\text { first-ever } \\
\text { ischaemic } \\
\text { strokes } \\
\text { avoided } \\
\text { each year in } \\
\text { a population } \\
\text { of one } \\
\text { million }\end{array}$} \\
\hline & & & Control & Intervention & & & & \\
\hline Nil & 988,000 & 1.0 & $0.14 \%$ & $\mathrm{~N} / \mathrm{A}$ & 0 & 0 & 0 & 0 \\
\hline $\begin{array}{l}\text { Blood pressure- } \\
\text { lowering (by } 10 \\
\mathrm{~mm} \mathrm{Hg} \text { systolic) }\end{array}$ & $\begin{array}{l}115,600 \\
(11.7 \%)\end{array}$ & $\begin{array}{l}3.6 \\
(2.2-5.8)\end{array}$ & $0.51 \%$ & $0.28 \%$ & $\begin{array}{l}46 \% \\
(35-55 \%)\end{array}$ & $0.23 \%$ & 266 & $19 \%$ \\
\hline $\begin{array}{l}\text { LDL-cholesterol } \\
\text { lowering (by I.0 } \\
\mathrm{mmol} / \mathrm{l} \text { ) }\end{array}$ & $\begin{array}{l}197,600 \\
(20 \%)\end{array}$ & 1.4 & $0.19 \%$ & $0.14 \%$ & $\begin{array}{l}36 \% \\
(22-48 \%)\end{array}$ & $0.05 \%$ & 99 & $7 \%$ \\
\hline $\begin{array}{l}\text { Anticoagulation } \\
\text { for atrial } \\
\text { fibrillation }\end{array}$ & $\begin{array}{l}4,887(50 \% \\
\text { of individuals } \\
\text { aged }>40 \\
\text { with AF) }\end{array}$ & 5.0 & $0.70 \%$ & $0.25 \%$ & $\begin{array}{l}64 \% \\
(49-74 \%)\end{array}$ & $0.35 \%$ & 22 & $2 \%$ \\
\hline $\begin{array}{l}\text { Cigarette smo- } \\
\text { king cessation }\end{array}$ & $\begin{array}{l}181,792 \\
(18.4 \%)\end{array}$ & $\begin{array}{l}1.9 \\
(1.6-2.2)\end{array}$ & $0.27 \%$ & $0.14 \%$ & $47 \%$ & $0.13 \%$ & 236 & $17 \%$ \\
\hline $\begin{array}{l}\text { Nicotine } \\
\text { replacement } \\
\text { therapy }\end{array}$ & $\begin{array}{l}5,454(3 \% \text { of } \\
181,792)\end{array}$ & $\begin{array}{l}1.9 \\
(1.6-2.2)\end{array}$ & $0.27 \%$ & $0.14 \%$ & $47 \%$ & $0.13 \%$ & 7 & $0.5 \%$ \\
\hline HbA $\mathrm{Ac}_{\mathrm{c}}$-lowering & $42,484(4.3 \%)$ & $\begin{array}{l}3.8 \\
(1.8-8.2)\end{array}$ & $0.53 \%$ & $0.49 \%$ & $\begin{array}{l}7 \% \\
(-6-19 \%)\end{array}$ & $0.04 \%$ & 17 & $1 \%$ \\
\hline
\end{tabular}

smoking were to reduce the relative risk of stroke by $47 \%,{ }^{30}$ it is possible that nicotine replacement therapy could save seven $(0.5 \%)$ of the I,400 first-ever strokes each year (Table 3).

Blood glucose-lowering The prevalence of diabetes in the UK population is about $4.3 \%,{ }^{47}$ which is about 42,484 individuals in a population of 988,000 stroke-free people. The adjusted relative risk of ischaemic stroke among people in the community with a history of diabetes is about 3.8 (95\% Cl: I.8-8.2). ${ }^{37}$ If the overall risk of firstever ischaemic stroke in the stroke-free population is $0.14 \%$ (see above), then the average annual risk of ischaemic stroke among diabetics is about $0.53 \%$ per year $(0.14 \% \times 3.8)$. If 42,484 diabetics have an annual risk of ischaemic stroke of $0.53 \%$, then they are likely to contribute 225 of the 1,400 (16\%) first-ever ischaemic strokes each year.

If lowering mean $\mathrm{HbA}_{\mathrm{lc}}$ by $0.9 \%$ is subsequently proven to be effective in reducing the risk of stroke by $7 \%$, as currently estimated, ${ }^{28}$ and if the 42,484 diabetics could be identified and treated with lifestyle modifications or medications that produce a sustained reduction in mean $\mathrm{HbA}_{\mathrm{lc}}$ concentration by $0.9 \%$, then stroke could be reduced from $0.53 \%$ (control) to $0.49 \%$ (glucoselowering therapy), RRR 7\%, ARR $0.04 \%$, realising a saving of 17 strokes each year $(42,484 \times 0.04 \%)$, which is
$1 \%$ of all 1,400 first-ever strokes in a population of one million (Table 3 ). ${ }^{28}$

Aspirin Aspirin is of uncertain net value in the primary prevention of stroke. ${ }^{33} \mathrm{~A}$ recent meta-analysis of six primary prevention trials of long-term aspirin vs control in 95,000 individuals at low average vascular risk and followed for 660,000 person years revealed that random allocation to aspirin was not associated with a significant reduction in first-ever ischaemic stroke (rate ratio 0.86 , 95\% Cl: $0.74-1.00$ ), nor any first stroke (rate ratio 0.95 , 95\% Cl: 0.85-1.06) compared with control. ${ }^{33}$ Although aspirin was associated with a significant reduction in any serious vascular event (stroke, myocardial infarction or vascular death), from $0.57 \%$ per year (control) to $0.51 \%$ per year (aspirin), rate ratio $0.88,95 \% \mathrm{Cl}: 0.82-0.94$, it was associated with a significant increase in major extracranial bleeding (rate ratio I.54, 95\% Cl: I.30-I.82)..$^{33}$

Carotid endarterectomy Carotid endarterectomy probably does not have net value in the primary prevention of stroke. A recent systematic review suggests that the prognosis of neurologically asymptomatic carotid stenosis is so favourable with best medical treatment nowadays (stroke rate $<1 \%$ per year) that the immediate risks of carotid revascularisation ( $2 \%$ perioperative stroke rate) are too great to offer any benefit of carotid endarterectomy for asymptomatic 
carotid stenosis. ${ }^{34}$ These conclusions are supported by recent data from a prospective, population-based study of I,I53 patients with TIA or stroke, of whom $10 \mathrm{I}$ $(8.8 \%)$ had a carotid stenosis $>50 \%$ that was neurologically asymptomatic. ${ }^{35}$ After a mean follow-up period of three years, the annual rate of ipsilateral ischaemic stroke with best medical treatment was only $0.34 \%(95 \% \mathrm{Cl}: 0.0 \mathrm{I}-$ $1.9 \%$, and the rate of disabling ipsilateral ischaemic stroke was $0.0 \%$ ( $95 \% \mathrm{Cl}: 0.0-1.0 \%){ }^{35}$

Summary The above calculations suggest that accurate identification and appropriate treatment of individuals at risk of stroke (the 'high-risk' approach), ${ }^{31}$ by means of lowering blood pressure and cholesterol, and anticoagulating high-risk individuals with atrial fibrillation, could save a substantial minority of the I,400 first-ever strokes each year (Table 3).

The 'population' or 'mass' approach, implemented for example by government legislation to minimise population exposure to causal vascular risk factors, is also likely to be effective and complementary. ${ }^{31}$ For example, government legislation to ban tobacco smoking in public indoor places in Scotland in March 2006 was associated with a $17 \%(95 \% \mathrm{Cl}$ : $16-18 \%)$ reduction in hospital admissions for acute coronary syndromes over the next 10 months compared with a $4 \%$ reduction in England (which had no smoking ban) over the same period. ${ }^{48}$ Similar legislation in Rome in January 2005 was also associated with a reduction in acute coronary events by II\% (7-15\%) among 35-64 year olds, and by $8 \%(3-12 \%)$ in $65-74$ year olds. ${ }^{49}$

\section{REFERENCES}

I Rothwell PM, Coull AJ, Silver LE et al. Population-based study of event-rate, incidence, case fatality, and mortality for all acute vascular events in all arterial territories (Oxford Vascular Study) Lancet 2005; 366: 1773-83. doi:10.1016/S0I40-6736(05)67702-1

2 Geddes JM, Fear J, Tennant A et al. Prevalence of self-reported stroke in a population in northern England. J Epidemiol Commun Health 1996; 50:140-3. doi:10.1 I36/jech.50.2.140

3 O'Mahony PG, Thomson RG, Dobson R et al. The prevalence of stroke and associated disability.J Public Health Med 1999; 21:16671. doi:10.1093/pubmed/21.2.166

4 Bamford J, Sandercock P, Dennis M et al. A prospective study of acute cerebrovascular disease in the community: the Oxfordshire Community Stroke Project 198I-1986. 2. Incidence, case fatality rates and overall outcome at one year of cerebral infarction, primary intracerebral and subarachnoid haemorrhage. J Neurol Neurosurg Psychiatry 1990; 53:16-22.

5 Anderson CS, Jamrozik KD, Broadhurst RJ et al. Predicting survival for one year among different subtypes of strokes: results from the Perth Community Stroke Study. Stroke 1994; 25:1935-44.

6 Wardlaw JM, Murray V, Berge E et al. Thrombolysis for acute ischaemic stroke. Cochrane Database Syst Rev 2009; 4: CD0002I3. doi: 10.1002//465|858.CD0002/3.pub2

7 Sandercock PAG, Counsell C, Gubitz GJ et al.Antiplatelet therapy for acute ischaemic stroke. Cochrane Database Syst Rev 2008; 3 : CD000029. doi: 10.1002//465/858.CD000029.pub2
The greater potential effects of prevention strategies, compared with treatment strategies, of ischaemic stroke in the model described above are consistent with those observed in population-based studies. ${ }^{13} \mathrm{~A}$ recent systematic review of 35 population-based studies in 18 high-income countries of the incidence of stroke from 1970 to 2008 showed a statistically significant decline in stroke incidence by $42 \%$ (or I\% per year), from 163 (95\% Cl: 98-227) per $100,000$ person years in 1970 to 94 (95\% Cl: $72-116)$ per 100,000 person years in 2008 ( $p$ for trend $=0.04$ ), presumably concurrent with reductions in population exposure to causal risk factors. ${ }^{13}$

These findings also support the initiative of the UK Department of Health to implement the UK National Health Service Health Check programme, whereby everyone aged 40-79 years who has not been diagnosed with a previous stroke, heart or kidney disease is invited, once every five years, to have their cardiovascular risk assessed using an absolute risk prediction tool, and given support and advice to help manage and reduce their cardiovascular risk..$^{50}$ The modelled incremental costeffectiveness of this intervention is $£ 2,480$ per qualityadjusted life year (QALY) gained, which is well below the threshold of about $£ 30,000$ per QALY gained. ${ }^{50}$

'An ounce of prevention is worth a pound of cure.' - Benjamin Franklin
8 Stroke Unit Trialists' Collaboration. Organised inpatient (stroke unit) care for stroke. Cochrane Database Syst Rev 2007; 4: CD000 197. doi: 10.1002/1465/858.CD000197.pub2

9 Hofmeijer J, Kappelle LJ, Algra A et al. Surgical decompression for space-occupying cerebral infarction (the Hemicraniectomy After Middle Cerebral Artery infarction with Life-threatening Edema Trial [HAMLET]): a multicentre, open, randomised trial. Lancet Neurol 2009; 8:326-33. doi:I0.1016/SI474-4422(09)70047-X

I0 Royal College of Physicians of London (RCPL). National sentinel stroke audit phase II (clinical audit) 2008. London: RCPL; 2009. Available from: http://www.rcplondon.ac.uk/clinical-standards/ceeu/ Current-work/stroke/Documents/stroke-audit-report-2008.pdf

II Huttner HB, Schwab S. Malignant middle cerebral artery infarction: clinical characteristics, treatment strategies, and future perspectives. Lancet Neurol 2009; 8:949-58. doi:I0.10I6/SI474-4422(09)70224-8

12 Sudlow C, Warlow C. Getting the priorities right for stroke care. BMJ 2009; 338:1419-22. doi: I0.1 I36/bmj.b2083

I3 Feigin VL, Lawes CM, Bennett DA et al. Worldwide stroke incidence and early case fatality reported in 56 population-based studies: a systematic review. Lancet Neurol 2009; 8:355-69. doi:I0.10I6/SI474-4422(09)70025-0

14 Chandratheva A, Mehta Z, Geraghty OC et al. Population-based study of risk and predictors of stroke in the first few hours after a TIA. Neurology 2009; 72:1941-7. doi:10.12/2/WNL.0b013e3181a826ad 
I5 Pendlebury ST, Rothwell PM. Risk of recurrent stroke, other vascular events and dementia after transient ischaemic attack and stroke. Cerebrovasc Dis 2009; 27 (Suppl 3): I-I I. doi:I0.I I59/000209260

16 Rothwell PM, Eliasziw M, Gutnikov SA et al. Pooled analysis of individual patient data from randomised controlled trials of endarterectomy for symptomatic carotid stenosis. Lancet 2003; 36I:107-16. doi:10.1016/S0140-6736(03) I2228-3

17 Rothwell PM. Poor outcomes after endovascular treatment of symptomatic carotid stenosis: time for a moratorium. Lancet Neurol 2009; 8:87I-3. doi:I0.10I6/SI474-4422(09)70230-3

I8 Algra A, van Gijn J. Cumulative meta-analysis of aspirin efficacy after cerebral ischaemia of arterial origin. J Neurol Neurosurg Psychiatry 1999; 66:255. doi: I 0.I I36/jnnp.66.2.255

19 Halkes PH, Gray LJ, Bath PM et al. Dipyridamole plus aspirin versus aspirin alone in secondary prevention after TIA or stroke: a metaanalysis by risk. J Neurol Neurosurg Psychiatry 2008; 79:1218-23. doi:I0.1 I36/jnnp.2008.143875

20 Halkes PHA, van Gijn, Kappelle LJ et al. Risk indicators for development of headache during dipyridamole treatment after cerebral ischaemia of arterial origin. J Neurol Neurosurg Psychiatry 2009; 80:437-9. doi:10.I I36/jnnp.2008.1479/8

21 Sacco RL, Diener H-C, Yusuf $S$ et al. Aspirin and extended-release dipyridamole versus clopidogrel for recurrent stroke. The Prevention Regimen for Effectively Avoiding Second Strokes (PRoFESS) trial. N Engl J Med 2008; 359:|238-5।. doi:I0.I056/ NEJMoa0805002

22 EAFT (European Atrial Fibrillation Trial) Study Group. Secondary prevention in non-rheumatic atrial fibrillation after transient ischaemic attack or minor stroke. Lancet 1993; 342: 1255-62.

23 Saxena R, Koudstaal PJ. Anticoagulants for preventing stroke in patients with nonrheumatic atrial fibrillation and a history of stroke or transient ischaemic attack. Cochrane Database Syst Rev 2003; 3: CD000185. doi: 10.1002//4651858.CD000185.pub2

24 Hart RG, Pearce LA, Aguilar MI. Meta-analysis: antithrombotic therapy to prevent stroke in patients who have nonvalvular atrial fibrillation. Ann Intern Med 2007; 146:857-67.

25 Law MR, Morris JK,Wald NJ. Use of blood pressure lowering drugs in the prevention of cardiovascular disease: meta-analysis of 147 randomised trials in the context of expectations from prospective epidemiological studies. BMJ 2009; 338:bl 665.

26 Messerli FH,Williams B, Ritz E. Essential hypertension. Lancet 2007 370:59I-603. doi:I0.10I6/S0I40-6736(07)6I299-9

27 Amarenco P, Labreuche J. Lipid management in the prevention of stroke: review and updated meta-analysis of statins for stroke prevention. Lancet Neurol 2009; 8:453-63. doi:I0.10I6/SI4744422(09)70058-4

28 Ray KK, Seshasai SRK, Wijesuriya S et al. Effect of intensive control of glucose on cardiovascular outcomes and death in patients with diabetes mellitus: a meta-analysis of randomised controlled trials. Lancet 2009; 373:1765-72. doi:I0.1016/S0I40-6736(09)60697-8

29 Röther J, Alberts MJ, Touzé E et al. Risk factor profile and management of cerebrovascular patients in the REACH Registry. Cerebrovasc Dis 2008; 25:366-74. doi:10.II59/000I20687

30 Shinton R, Beevers G. Meta-analysis of relation between cigarette smoking and stroke. BMJ 1989; 298:789-94. doi:|0.|136/ bmj.298.6676.789

31 Rose G. Strategy of prevention: lessons from cardiovascular disease. BMJ I98I; 282: I847-5I. doi:I0.I |36/bmj.282.6279.1847

32 Connolly SJ, Ezekowitz MD,Yusuf $S$ et al. Dabigatran versus warfarin in patients with atrial fibrillation. $N$ Engl J Med 2009; 36I:II39-5I. doi:I0.1056/NEJMoa090556I
33 Antithrombotic Trialists' Collaboration. Aspirin in the primary and secondary prevention of vascular disease: collaborative metaanalysis of individual participant data from randomised trials. Lancet 2009; 373:I849-60. doi:I0.1016/S0I40-6736(09)60503-I

34 Abbott A. Medical (nonsurgical) intervention alone is now best for prevention of stroke associated with asymptomatic severe carotid stenosis. Results of a systematic review and analysis. Stroke 2009; 40:e573-83. doi:I0.1 I6I/STROKEAHA.109.556068

35 Marquardt L, Geraghty OC, Mehta Z et al. Low risk of ipsilatera stroke in patients with asymptomatic carotid stenosis on best medical treatment. A prospective, population-based study. Stroke 20I0; 4I:ell-7.

36 Standing P, Deakin H, Norman P et al. Hypertension - its detection, prevalence, control and treatment in a quality driven British general practice. Br J Cardiol 2005; 12:47I-6.

37 Jamrozik K, Broadhurst RJ, Anderson CS et al. The role of lifestyle factors in the etiology of stroke. A population-based case-control study in Perth, Western Australia. Stroke 1994; 25:5I-9.

38 Lawes CM, Vander Hoorn S, Rodgers A, International Society of Hypertension. Global burden of blood-pressure-related disease, $200 \mathrm{I}$. Lancet 2008; 37I:I5I3-8. doi:I0.1016/S0I40-6736(08)60655-8

39 Tolonen $\mathrm{H}$, Keil U, Ferrario $M$ et al. Prevalence, awareness and treatment of hypercholesterolaemia in 32 populations: results from the WHO MONICA Project. Int J Epidemiol 2005; 34:I8I-92. doi:10.1093/ije/dyi056

40 Bronner LL, Kanter DS, Manson JE. Primary prevention of stroke. N Engl J Med 1995; 333:I392-400. doi:I0.1056/NEJMI995II233332I06

4I Brugts JJ, Yetgin T, Hoeks SE et al. The benefits of statins in people without established cardiovascular disease but with cardiovascular risk factors: meta-analysis of randomised controlled trials. BMJ 2009; 338:b2376. doi:10.1136/bmj.b2376

42 Feinberg WM, Blackshear JL, Laupacis A et al. Prevalence, age distribution, and gender of patients with atrial fibrillation: analysis and implications. Arch Intern Med 1995; I55:469-73. doi:I0.I00I/ archinte. 155.5.469

43 Wolf PA, Abbott RD, Kannel WB. Atrial fibrillation as an independent risk factor for stroke: the Framingham Study. Stroke 1991; 22:983-8.

44 Wolf PA, Mitchell JB, Baker CS et al. Impact of atrial fibrillation on mortality, stroke and medical costs. Arch Intern Med 1998; I58:229-34. doi:I0.1001/archinte. I58.3.229

45 http://www.statistics.gov.uk/cci/nugget.asp?ID=6

46 Moore D, Aveyard P, Connock $M$ et al. Effectiveness and safety of nicotine replacement therapy assisted reduction to stop smoking: systematic review and meta-analysis. BMJ 2009; 338:bl024. doi:I0.1 I36/bmj.bl024

47 González EL, Johansson S, Wallander MA et al. Trends in the prevalence and incidence of diabetes in the UK: 1996-2005. J Epidemiol Community Health 2009; 63:332-6. doi:10.11361 jech.2008.080382

48 Pell JP, Haw S, Cobbe S et al. Smoke-free legislation and hospitalizations for acute coronary syndrome. N Engl J Med 2008; 359:482-9I. doi:I0.1056/NEJMsa0706740

49 Cesaroni G, Forastiere F, Agabiti N et al. Effects of the Italian smoking ban on population rates of acute coronary events. Circulation 2008; I I7: I I83-88. doi:I0. I I6I/CIRCULATIONAHA. 07.729889

50 Department of Health. Putting prevention first - vascular checks: risk assessment and management. London: DOH; 2008. Available from: http://www.dh.gov.uk/prod_consum_dh/groups/ dh_digitalassets/@dh/@en/documents/digitalasset/dh_090278.pdi 